\title{
Distributions Implied by Exchange Traded Options: A Ghost's Smile?
}

\author{
Martin CINCIBUCH - Czech National Bank, Prague (Martin.Cincibuch@cnb.cz)
}

Risk neutral distributions summarise much of the available information associated with market prices and therefore they are attractive for market, academic and central bank economists. As Bliss and Panigirtzoglou (2000) note, RNDs estimated from liquid assets may be used by market participants for pricing exotic derivatives. Further, from the point of view of the central bank, option markets provide information in addition to that provided by spot and futures markets, and implied risk neutral distributions represent a convenient tool for interpreting this additional information. Clews, Panigirtzoglou and Proudman (2000) describe the methods used at the Bank of England for estimating distributions implied by interest rate futures, which enter as a regular input at its Monetary Policy Committee briefings. At other central banks, RNDs are estimated from currency options and used for monitoring the foreign exchange market, for example, at the Bank of Canada or the Czech National Bank.

Next, due to the forward-looking nature of option prices, accurate estimates of implied distributions might arguably enhance VaR modelling. There is an increasing amount of literature pointing to the shortcomings of risk modelling based on the assumption that market price data follow a stochastic process which only depends on past observations. (e.g. Danielsson (2000), Ahn et. al. (1999), Artzner et. al. (2000)). On the other hand, empirical evidence suggests that option-based measures of uncertainty are a better predictor of future volatility of the underlying asset than statistical time-series models. Christensen and Prabhala (1998) offer such evidence for S\&P index options; Jorion (1995) for currency options for major currency pairs; and Bouc and Cincibuch (2001) for Czech koruna options. The question whether options also carry useful information about the fat-tailedness of the distribution of future assets' returns and about other deviations from lognormality is an important one from the risk management point of view. And indeed, the first step to answering such a question is to have a reliable estimate of the risk neutral distribution implied by the option prices.

The results presented in this article are threefold. First, we discuss a new method for estimating risk neutral distributions (RND) implied by American futures options. In contrast to other methods that utilise lower and upper bounds for the prices of American options, this method amounts to inverting the Barone-Adesi and Whaley method (1987) (BAW method) to get the BAW implied volatility from the option prices and then approximating the BAW volatility smile with the weighted smoothing spline. Using the full history of yen futures options traded on the Chicago Mercantile Exchange (CME) and comparing them with relevant option prices from the interbank over-the-counter (OTC) market, we found good support for the hypothesis that the BAW volatility implied by a American futures option does not differ significantly from the Black-Scholes volatility implied by the price of the European option with the same exercise price and maturity. Further and more importantly, we found that BAW volatilities derived from a pair of put and call CME options with the same exercise price are very close to each other. Indeed, the model independent and arbitrage based put-call parity stipulates that Black-Scholes volatilities implied by European puts and calls with the same exercise price are equal. Therefore, we argue 
that the BAW inversion leads to an appropriate „European“ volatility smile and that the approach is a legitimate RND estimation method. The method is numerically stable and easy to apply, and it circumvents convergence problems often encountered with parametric methods.

Second, by investigating the CME and OTC markets in parallel, we gained insight on the structure and interaction of the two markets. Intensive arbitrage seems to take place more for certain exercise prices than for others, which may be explained by the varying OTC liquidity over the price space. It leads to price distortions and an ensuing interesting „ghost-like“ shape of the RND density implied by CME options.

Third, using these empirical results, we show how it is possible to improve RND estimation from a low number of OTC option prices. In the literature, two quadratic extrapolation methods have been suggested, but they either break the non-arbitrage constraints imposed on the volatility function or they do not fit well the observed CME data. To overcome this problem, we suggest a parsimonious generalisation of these methods, which significantly improves the fit.

An improved way of estimating foreign exchange RNDs from the OTC market is useful, because data from this market have several convenient features from the practical point of view. In general, the OTC FX market is quite deep, and contrary to exchange traded options, it exists for most currencies. In addition, OTC quotes are usually available for fixed maturities. However, it is often the case that only a limited number of benchmark exercise prices are readily accessible from the OTC market and therefore some extrapolation has to be made. In essence, we enhance this extrapolation by information from CME prices.

\section{REFERENCES}

AHN, D. H. - BOUDUKH, J. - RICHARDSON, M. - WHITELAW, R. F. (1999): Optimal Risk Management Using Options. Journal of Finance, vol. 54, no. 1, pp. 359-375.

ARTZNER, P. - DELBAEN, F. - EBER, J. - HEATH, D. (1999): Coherent Measure of Risk. Mathematical Finance, vol. 9, 1999, pp. 203-228.

BARONE-ADESI, G. - WHALEY, R. E. (1987): Efficient analytic approximation of American option values. Journal of Finance, vol. 32, 1987, pp. 301-320.

BLISS, R. R. - PANIGIRTZOGLOU, N. (2000): Testing the Stability of Implied Probability Density Functions. Bank of England Working Paper, 2000, no. 114.

BOUC, P. - CINCIBUCH, M. (2001): Interpretation of Czech FX Options. Czech National Bank, Prague, WP, 2001 , no. 36 .

CHRISTENSEN, B. J. - PRABHALA, N. R. (1998): The Relation between Implied and Realized Volatility. Journal of Financial Economics, vol. 50, 1998, pp. 125-150.

CLEWS, R. - PANIGIRTZOGLOU, N. - PROUDMAN, J. (2000): Recent Developments in Extracting Information from Options Markets. Bank of England Quarterly Bulletin, vol. 40, February 2000, no. 1, pp. 50-57.

DANIELSSON, J. (2000): The Emperor Has No Clothes: Limits to Risk Modelling. Financial Markets Group of London School of Economics - mimeo

EBRD (1999): Transition Report: 1999. London, EBRD, 2000.

JORION, P. (1995): Predicting Volatility in the Foreign Exchange Market. Journal of Finance, vol. 50, 1995, no. 2, pp. 507-528. 
JEL Classification: G13, G14, G15, F31

Keywords: American options - futures - OTC - implied distributions - efficiency

\title{
Distributions Implied by Exchange-Traded Options: A Ghos- t's Smile?
}

\author{
Martin CINCIBUCH - Czech National Bank, Prague (Martin.Cincibuch@cnb.cz)
}

The paper proposes a new and readily applicable method for estimating risk-neutral distributions (RND) implied by American futures options. It amounts to inverting the Barone-Adesi and Whaley (BAW) method to get a BAW-implied volatility „smile.“ Extensive empirical tests show that the BAW smile is equivalent to the volatility smile as implied by corresponding European options. Therefore, the procedure leads to a legitimate RND-estimation method. Further, an investigation of currency options as traded both on the Chicago Mercantile Exchange (CME) and on over-the-counter (OTC) markets provides insights into the structure and interaction between the markets. Unequally distributed liquidity on OTC markets seem to lead to price distortions and an ensuing „ghost-like“ shape of RND as implied by CME options. Finally, using empirical results, the author proposes a parsimonious generalization of the existing methods for estimating volatility smiles based on OTC options. A single, free parameter significantly improves the regression. 